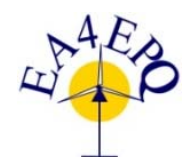

International Conference on Renewable Energies and Power Quality (ICREPQ'17)

Malaga (Spain), $4^{\text {th }}$ to $6^{\text {th }}$ April, 2017

Renewable Energy and Power Quality. Gournal (RE\&PQJ)

ISSN 2172-038 X, No.15 April 2017

\title{
Utilization of residual heat in Diesel engines, CFD simulation of a thermoelectric generator
}

\author{
L. Montoro, A. Massaguer, E. Massaguer, M. Comamala, R. Fernández, A. Deltell \\ University of Girona \\ C. de Maria Aurèlia Capmany 62, 17071 Girona (Spain) \\ e-mail: lino.montoro@udg.edu
}

\begin{abstract}
The present research shows the results obtained in the validation tests of a thermoelectric module that works with a diesel 1800 cubic centimeters engine exhaust gases. A receptacle connected to an exhaust gas pipe was manufactured for the tests. This adapter allowed tests of heatsinks. We compared the experimental data with those provided by the CFD program (ANSYS CFX). The information given by the simulation software is similar to the given by experimental tests, in particular the data obtained using the k- $\varepsilon$ turbulence model.
\end{abstract}

\section{Key words}

Thermoelectric generator, TEG module, Waste heat recovery, Diesel engine, CFD simulation.

\section{Introduction}

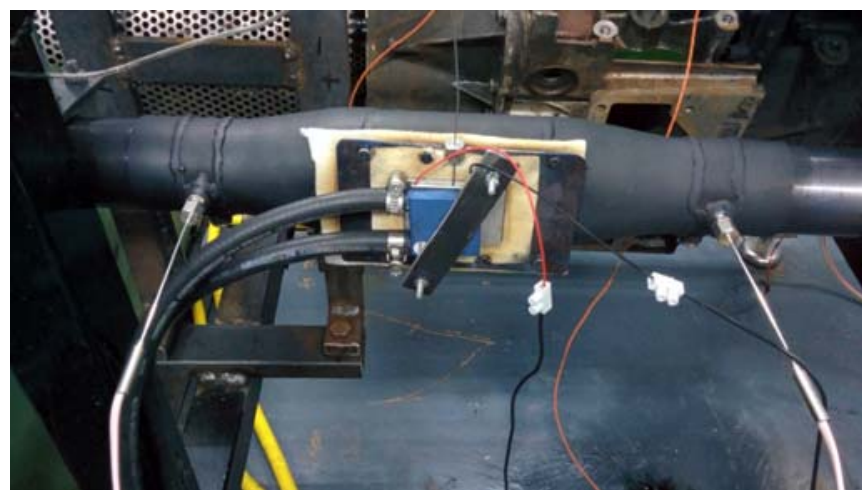

Fig. 1. Experimental device.

Nowadays, numerous studies [1-6] are focused on the use of residual heat from combustion engines through the use of thermoelectric modules (TEGs). The objective of the present work is to validate the use of simulation software, in particular ANSYS CFX, for this type of tests

An experimental setup has been prepared for the study of a thermoelectric module, figures 1 and 2 , this receptacle allows the combustion gases of an $1800 \mathrm{cc}$ diesel engine to be brought into contact with a heat sink that transfers the heat from the fumes to the TEG.

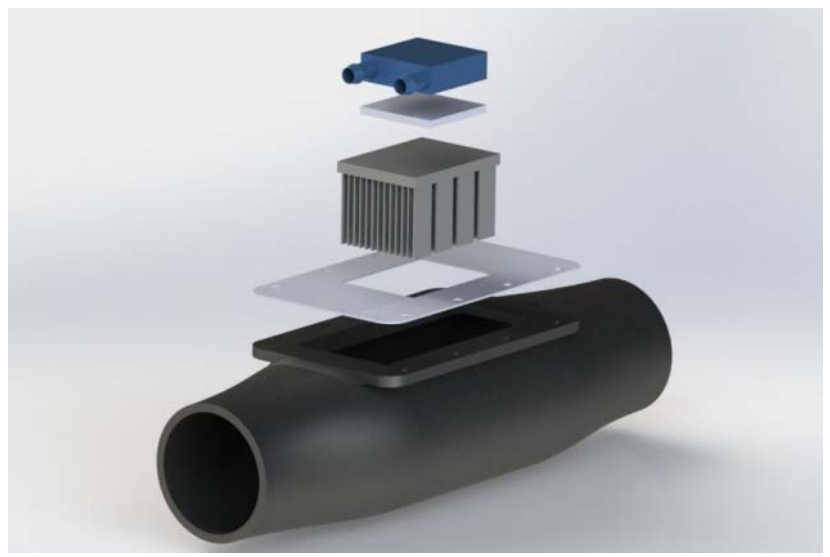

Fig. 2. Schematic of the experimental device.

Using the SolidWorks program, a working geometry has been generated for CFD simulation, considering mass flow rates of exhaust fumes, cooling water flow rates, and working temperatures. We have also introduced the different materials that make up each of the parts of the assembly.

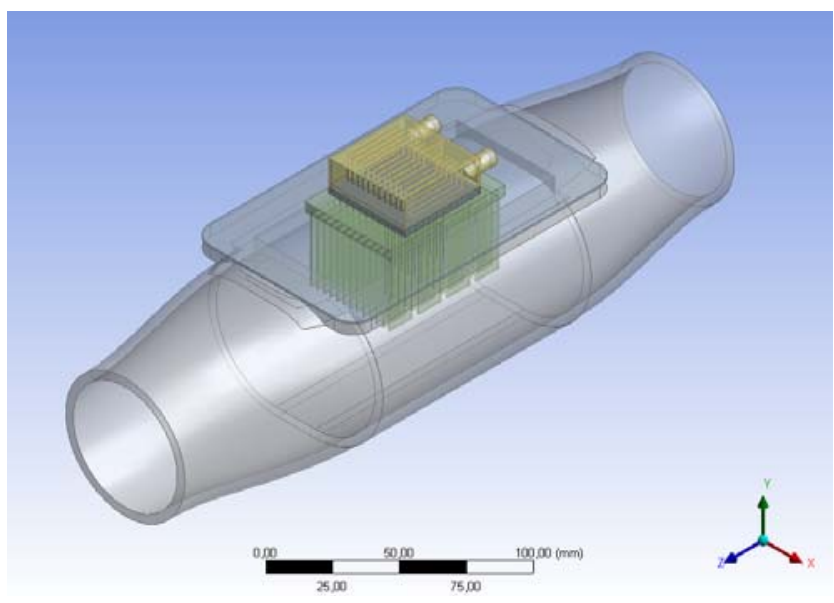

Fig. 3. ANSYS CFX model. 
Tests have been carried out on an engine test bench, where exhaust gas temperature measurements have been performed at different engine speeds. Simultaneously, the temperatures of the thermoelectric module and the generated electrical power have been quantified.

\section{Method}

The thermoelectric module TEG126-40B of the company EVERREDtronics. has been selected to carry out the tests. This module has dimensions of $40 \times 40 \times 4.5 \mathrm{~mm}$ and, according to the manufacturer's specifications, generates $6.8 \mathrm{~W}$ of power, working at a temperature of $50^{\circ} \mathrm{C}$ on the cold side and at a $300^{\circ} \mathrm{C}$ on the hot side. A small aluminum heat exchanger of $40 \times 40 \times 10 \mathrm{~mm}$ has been selected, in order to keep constant the cold side temperature. This device is equipped with two $6 \mathrm{~mm}$ diameter ducts that allow the cooling fluid (water) circulation. The cooler has welded baffles that force the cooling fluid flow, increasing the contact surface between aluminum and water, and maximizing the total heat transfer coefficient.

In order to capture the maximum amount of heat from the exhaust gases, the hot face of the thermoelectric module consists of a $42 \times 42 \times 30 \mathrm{~mm}$ aluminum heatsink, with 13 units of $42 \times 28 \times 0.8 \mathrm{~mm}$ fins, oriented in the direction of exhaust gases flow. The thermoelectric module, and the heat sinks of the hot face and the cold face are connected by means of M4 screws, which guarantee a perfect contact and the maximum heat transfer through the three bodies.

Elements used in the test device have been completely $\mathrm{s}$ dimensioned and plotted using the CAD software Solidworks. The generated CAD geometries are essential for an accurate simulation, so, they have to be as close to reality as possible.

The ANSYS Workbench software and in particular the CFD ANSYS CFX CFD tool was used. This program simulates the movement of the combustion gases inside the duct and all the heat transfer phenomena: gas-solid, solidsolid and solid-liquid and finally the movement of the cooling water. To perform the simulation the three domains have been meshed using tetrahedral elements of variable size, adjusting with smaller sizes to the areas of heat transfer mentioned above. The total number of elements exceeds 1.35 million of tetrahedrons. Stationary state simulations have been performed, considering two different turbulence models, such as k-epsilon and SST.

A Diesel engine, without turbo, EGR system and without particle trap system was used for the tests. The engine crankshaft is coupled to an eddy current brake, to reproduce multiple working conditions, similar to what an automobile would have during its normal operation.
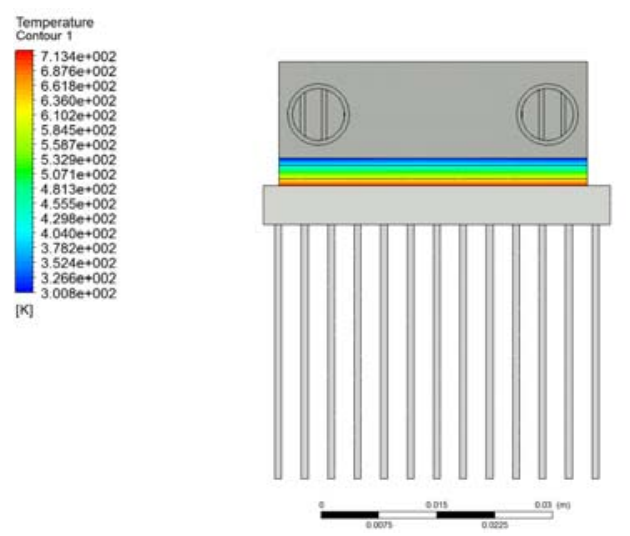

Fig. 4. Temperature gradient in the module (simulated).

\begin{tabular}{ccccc}
\hline Exp. & Theoretical & $\begin{array}{c}\text { Simulatio } \\
\mathbf{n} \\
(\mathbf{k}-\boldsymbol{\varepsilon})\end{array}$ & $\begin{array}{c}\text { Simulation } \\
\text { (SST) }\end{array}$ & Experimental \\
\hline neutral & 87,64 & 86,85 & 85,95 & 87,00 \\
1 & 110,53 & 109,35 & 108,25 & 105,42 \\
2 & 122,94 & 121,95 & 120,85 & 118,46 \\
3 & 133,77 & 132,55 & 131,25 & 129,12 \\
4 & 164,03 & 162,45 & 160,95 & 157,24 \\
\hline 5 & 259,19 & 256,95 & 254,85 & 248,46 \\
6 & 372,31 & 369,26 & 346,75 & 355,08 \\
\hline
\end{tabular}

Table 1. Comparative results (temperatures in Celsius degrees)

Tests have been carried out at different engine loads, measuring the temperatures of the fluid streams as well as the circulating mass flow rates. It has reached a power developed by the motor of $30 \mathrm{~kW}$ since, for higher powers, the obtained temperatures could deteriorate the thermoelectric module.

The experimental temperatures (figure 4,5 and table 1) have been compared with two different models of turbulence, in addition, they have been compared with those provided by the theory of heat transfer [7] (conduction and convection in fins).

\section{Conclusions}

After the analysis of the results, it can be concluded that CFD tools allow a reliable estimation of the TEG response during its operation; its use in the optimization of residual heat saving devices in vehicles will reduce design time and improve their performances.

\section{Results}




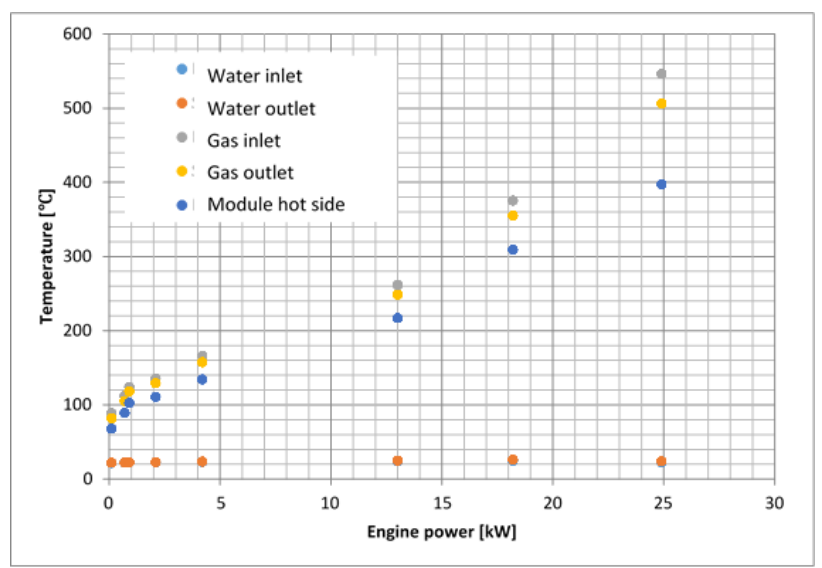

Fig. 5. Temperatures vs engine power.

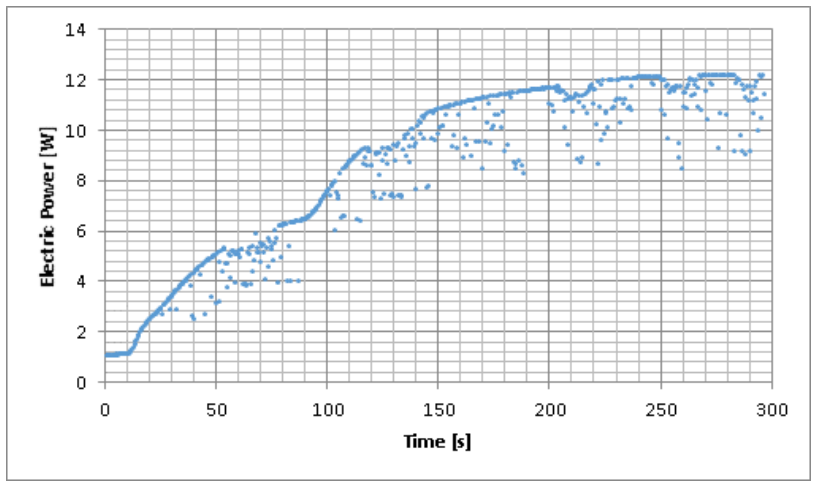

Fig. 6. Maximum electric power generated.

\section{Acknowledgement}

This work has been partially funded by the University of Girona under grant MPCUdG2016-4.

\section{References}

[1] M. Hatami, D.D. Ganji and M. Gorji-Bandpy, "A review of different heat exchangers designs for increasing the diesel exhaust waste heat recovery", Renewable and Sustainable Energy Reviews 2014, Vol. 37, pp. 168-181.

[2] O. Högblom and R. Andersson, "Analysis of thermoelectric generator performance by use of simulations and experiments", Journal of Electronic Materials 2014, Vol. 43, pp. 2247-2254.

[3] Y.Y. Hsiao, W.C. Chang and S.L. Chen. "A mathematic model of thermoelectric module with applications on waste heat recovery from automobile engine", in Energy 2010, Vol. 35, pp. 1447-1454.

[4] M.H. Elsheikh, D.A. Shnawah, M.F. Mohd Sabri, S. B. Mohd Said, M. H. Hassan, M. B. Ali Bashir and M. Mohamad, "A review on thermoelectric renewable energy: Principle parameters that affect their performance", Renewable and Sustainable Energy Reviews 2014, Vol. 30, pp. 337-355.

[5] J. M. Gordon, "Generalized power versus efficiency characteristics of heat engines: Ther thermoelectic generator as an instructive illustration", American Journal of Physics 1991, Vol. 59, pp. 551-555.

[6] C-T. Hsu, G-Y. Huang, H-S. Chu, B. Yu and D-J. Yao, "An effective Seebeck coefficient obtained by experimental results of a thermoelectric generator module", Applied Energy 2011, Vol. 88, pp. 51735179 .

[7] Theodore L. Bergman, Adrienne S. Lavine, Frank P. Incropera, David P. Dewitt, Fundamentals of Heat And Mass Transfer, John Wiley and Sons, 2011. 